\title{
Suitability assessment of protective clothing for ginning process workers
}

Sudha Babel, Rupali Gupta and Latika Sachihar

Received: 22.12.2017; Revised: 23.03.2018; Accepted: 11.04.2018

See end of the paper for authors' affiliations

Sudha Babel

Department of Textile and

Apparel Designing, College of

Home Science, Maharana Pratap

University of Agriculture and

Technology, Udaipur (Rajasthan)

India
ABSTRACT : The present paper is outcome of the research work under taken in All India Coordinated Research Project -Clothing and Textile (AICRP-CT) on mitigating occupational hazards. Here protective clothing and accessories were developed and field tested to assess the suitability among ginning mill workers. Two aprons, five masks, two types of hand gloves and ear muff for male workers were designed, developed and field tested during threshing to find out the suitability. The results of study revealed that developed functional clothing and accessories were found highly suitable by the cotton ginning workers.

KEY WORDS: Functional clothing, Ginning, Face mask, Occupational hazards

- HOW TO CITE THIS PAPER : Babel, Sudha, Gupta, Rupali and Sachihar, Latika (2018). Suitability assessment of protective clothing for ginning process workers. Asian J. Home Sci., 13 (1) : 108-113, DOI: 10.15740/HAS/AJHS/13.1/108-113. Copyright@ 2018: Hind Agri-Horticultural Society. 